\title{
Buckling Analysis of Hybrid Composite Propeller Shaft
}

\author{
Shivanand $^{1}$, Shravankumar B. Kerur ${ }^{2}$ \\ ${ }^{1,2}$ Department of Mechanical Engineering, Basaveshwara Engineering College, Bagalkot-587101 \\ Karnataka, India. (Visweshwaraya Technological University Belagavi, Karnataka, India)
}

\begin{abstract}
The purpose of the Present work is to find the buckling characteristics of Hybrid composite Propeller Shaft made up of low carbon steel, epoxy, S- glass and T700 fiber which can replace the conventional propeller shaft made of steel. Models of both steel propeller shaft and the hybrid composite propeller shafts are created and then buckling analysis is carried out using ANSYS 14.5. Comparative results show that Hybrid Composite shaft has got maximum load multiplier value than the steel shaft which means that the Hybrid composite shaft can sustain more torsional load compare to steel shaft. Therefore from the results we can conclude that the conventional steel shafts can be replaced by the Hybrid composite shafts so that we can reduce the weight of the propeller shaft which ultimately increases the performance of the automobiles and air vehicles.
\end{abstract}

Keywords: Hybrid composite Propeller Shaft, ANSYS 14.5, buckling analysis

\section{INTRODUCTION}

The propeller shaft is a component used for transmitting mechanical power, torque, and rotation. Drive shafts are used differently in different vehicles, with different configurations for front-wheel drive, four-wheel drive in automobiles. As torque carriers, drive shafts are subject to torsion and shear stress. Therefore they need to be strong enough to withstand the torsional loads. The purpose of the propeller shaft is to transmit torque from the transmission to the differential gear and hence it must be capable of rotating at very high speed required by the vehicle [1]. The drives shaft must also operate through constantly changing the angles between the transmission, the differential and the axels. The length of the drive shaft must also be capable of changing while transmitting torque. The drive shaft should provide a smooth, uninterrupted flow of power to the axles. The propeller shaft should satisfy three design specifications such as torque transmission capability, buckling torque capability and bending natural frequency. The specifications of the composite propeller shaft of an automotive transmission are same as that of the steel propeller shaft for optimal design.

Buckling analysis is a technique used to determine buckling loads (critical loads) at which a structure becomes unstable. The purpose of the Present work is to design, analyze and find the buckling characteristics of Hybrid composite Propeller Shaft made up of low carbon steel, epoxy, S- glass and T700 fiber [2], which can replace the conventional propeller shaft made of steel.

\section{LITERATURE REVIEW}

In the recent study by Kishor Ghatage, Narayanrao Hargude[3], the advanced composite materials such as Boron, Graphite, Carbon, Kevlar and Glass with suitable resins are used for automotive and other industrial applications especially for rotor applications because of their high specific strength (strength/density) and high specific modulus (modulus/density). Polymer matrix composites were proposed for light weight shafts in drivelines for automotive, industries.

T.Ravi , P.Kanagaraj [4], conducted the study on Numerical and Buckling Analysis of Composite Hybrid Propeller Shaft and found that the composites structures have many advantages because of higher stiffness and strength. This work dealt with the replacement of conventional steel drive shafts with a hybrid aluminum/carbon fibre propeller shaft for an automotive application and was developed with a new manufacturing method.

Mr. A.R. Nadaf, Dr.V.A.Raikar [5], described the Design \& Analysis of Composite Shaft of Passenger Vehicle. The automotive industry is exploring composite materials technology for structure component in order to obtain reduction of weight. This work dealt with replacement of conventional steel driveshaft with e-glass/ epoxy, carbon/ epoxy and hybrid composite driveshaft. In this study shaft is designed successfully for both steel and composite driveshaft. Shaft is analyzed using FEA software ANSYS and applied to minimize the weight of shaft which is subjected to constraints such as torque transmission, buckling torque, critical speed and fundamental natural frequency. 
Amim Altaf Baig, Dr. A.M. Langde [6], analyzed the failure of a Propeller Shaft for HMV (Heavy Motor Vehicle). The known material will provide the information such as density of material, modulus of elasticity and tensile strength of a drive shaft required for the software to perform the stress and failure analysis. To optimize the shaft for better performance and make it more durable, one must determine the cause of failure and predict the fatigue life to prevent future occurrence and to improve the performance of the Drive Shaft.

Dr.R.Ganapathi, Dr.B.Omprakash, J.Vinay Kumar [7] studied the modeling and analysis of composite drive shaft by replacing the conventional stainless steel with composite materials. They used composite materials in order to make a single long continuous shaft instead of conventional two piece steel drive shaft.

M. Pallavi et.al, [8] described the static and dynamic analysis of steel propeller shaft and composite propeller shaft made of glass fiber reinforced polymer. Primary objective was to match the torque bearing capacity, stiffness and weight savings of composite propeller shaft therewith of steel propeller shaft. The design constraints are angle of twist and natural frequency.

Atul Kumar Raikwar, Prof. Prabhash Jain \& Rajkumari Raikwar [9] conducted a study on Design and optimization of automobile propeller shaft with composite materials using FEM Analysis. The weight was optimized up to the $82.04 \%$ as compared to conventional propeller shaft material.

Miss Priya Dongare, Dr. Suhas Deshmukh, [10] dealt with the static and modal analysis of composite drive shaft and development of regression equations. In this work an attempt was made to evaluate the suitability of composite material such as carbon/epoxy for drive shaft in automotive transmission.

Srikanth Reddy [11] dealt with design and analysis of a drive shaft. Presently used materials in the market for manufacturing are cast iron, cast steel. The purpose of this paper was to design the drive shaft made of Ni-Cr steel and compare it with steel material. The design was done in Solid works software and analyzed using ANSYS.

Sheik A. N. S [12] conducted study to replace a forged steel drive shaft by a composite drive shaft with enhanced mechanical property with less weight. In this paper aluminum was chosen as matrix metal of composite, and reinforcement materials are aluminum oxide $\left(\mathrm{Al}_{2} \mathrm{O}_{3}\right)$ and zirconium diboride $\left(\mathrm{Z}_{\mathrm{r}} \mathrm{B}_{4}\right)$ was fabricated.

G V Mahajan [13] in this paper design and vibration analysis of composites propeller shafts was undertaken. The aim was to replace a metallic drive shaft by a composite shaft. V. S. Bhajantri [14] also carried out a study in order to replace the steel shaft by composite shaft. In this work optimization of stacking sequence was done. Comparison was done for steel and composite shaft for max stress and deflection and concluded that the change in fiber orientation angle, varies the stress.

Bhirud Pankaj Prakash [15] studied that by using of composite material in shaft leads to significant saving in weight. In their work, weight reduction was carried out by using composite shaft to $2.7 \mathrm{~kg}$ from $10 \mathrm{~kg}$ of steel drive shaft. Sagar R Dharmadhikari [16] paper deals with the review of optimization of drive shaft using the genetic algorithm and ANSYS.

\section{MATERIALS AND MODELING}

We know the importance of propeller shaft in automobiles. In the present work we are modeling two Propeller shafts one is steel and the other is composite one. Here we are going to discuss the Geometric considerations and design parameters for both the shafts and then the models are taken for meshing and analysis.

\begin{tabular}{|l|l|}
\hline \multicolumn{2}{|l|}{ Table 1: Properties of Steel } \\
\hline Young's Modulus & $210 \mathrm{Gpa}$ \\
\hline Shear Modulus & $80 \mathrm{Gpa}$ \\
\hline Poisson's Ratio & 0.3 \\
\hline Density & $7860 \mathrm{~kg} / \mathrm{m} 3$ \\
\hline Yield Strength & $370 \mathrm{Mpa}$ \\
\hline
\end{tabular}

\subsection{Modeling of steel propeller shaft}

Propeller shafts are designed on the basis of torsional loading. The commonly used materials for manufacturing the propeller shaft is low carbon steel with 10-18\% Chromium and 5-8 \% Nickel. The yield strength of the material should be of $370 \mathrm{~N} / \mathrm{mm}^{2}$ used for manufacturing propeller shaft is: The geometry for the steel propeller shaft is taken from the literature survey. The geometric dimensions, 3D Model and Mechanical properties for steel shaft are shown below. 
Vol. 8, Issue 12, December 2021

DOI: 10.17148/IARJSET.2021.81206

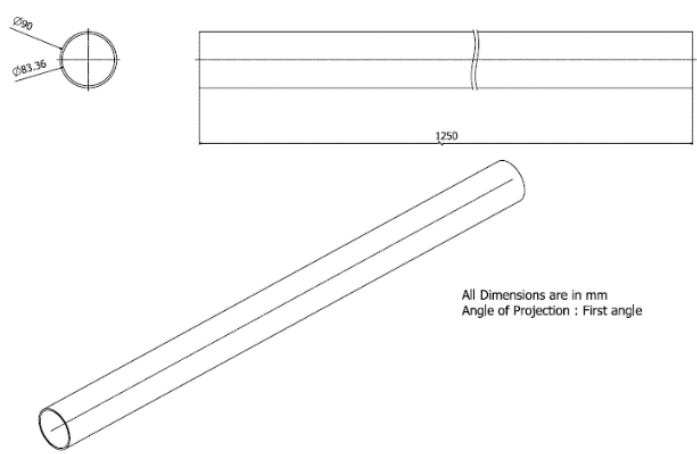

Fig 1: 3D Model of Steel Propeller Shaft

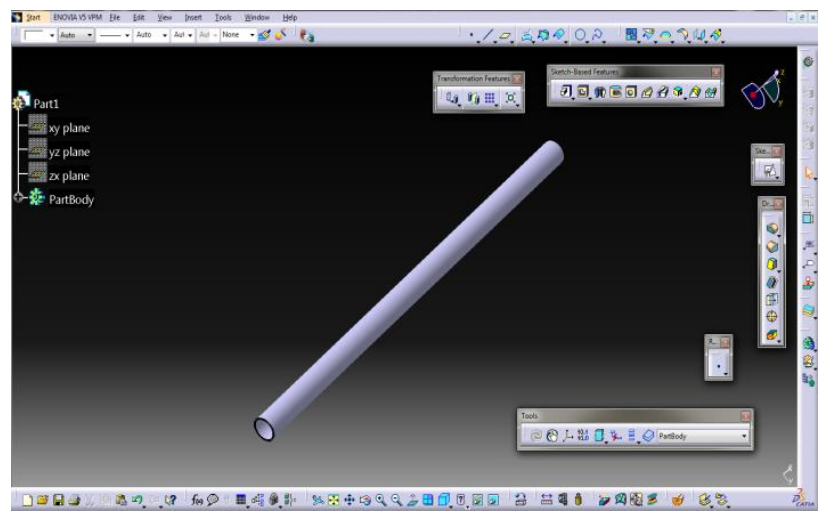

Fig 2: Geometric Dimension

Modeling of the steel propeller shaft is done using CATIA V5 R21. The outer diameter of the Steel propeller shaft is $90 \mathrm{~mm}$, inner diameter is $83.36 \mathrm{~mm}$ and length is $1250 \mathrm{~mm}$.

\subsection{Modeling of composite propeller shaft.}

The composite drive shaft should satisfy the design specifications such as static torque capability. The materials used for Hybrid Composite shaft in the present work are Low carbon Steel, S-Glass, Epoxy and T-700 fiber. The major role of Low carbon steel is to sustain the applied torque while the role of the carbon fiber epoxy composite is to increase bending strength. Modeling of the hybrid composite propeller shaft is done using ansys.

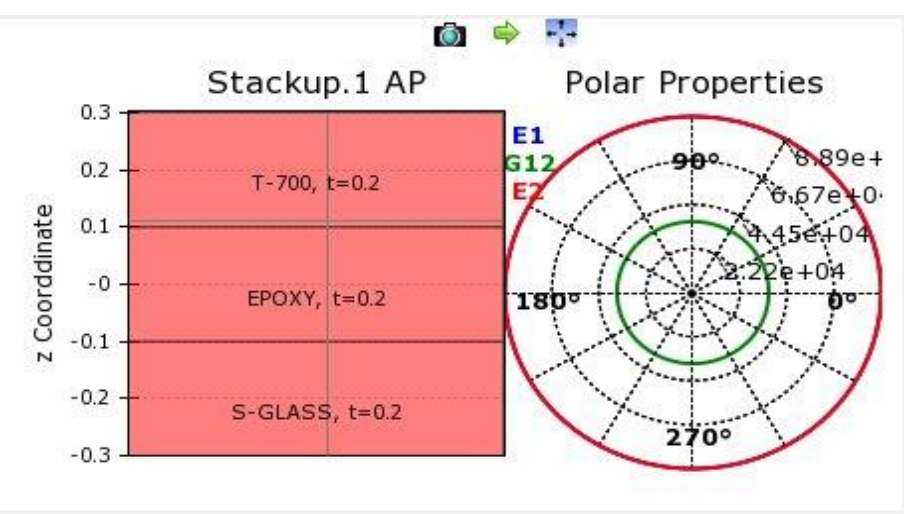

Fig 3: ACP post steps for adding layers

\section{CODE VALIDATION}

The problem is solved using Finite Element Analysis, the existing code is validated with the results of Mr. Swapnil Shinde[17], for accuracy and correctness. For the modeling of Steel Propeller Shaft, the inner and outer diameters are considered along with that the length of the shaft also considered, for analysis static and modal analysis have been carried out and for the same parameters validation is carried out. It is found that it agrees well with the results of published works. The result comparison for code validation is shown below. 
DOI: $10.17148 /$ IARJSET.2021.81206

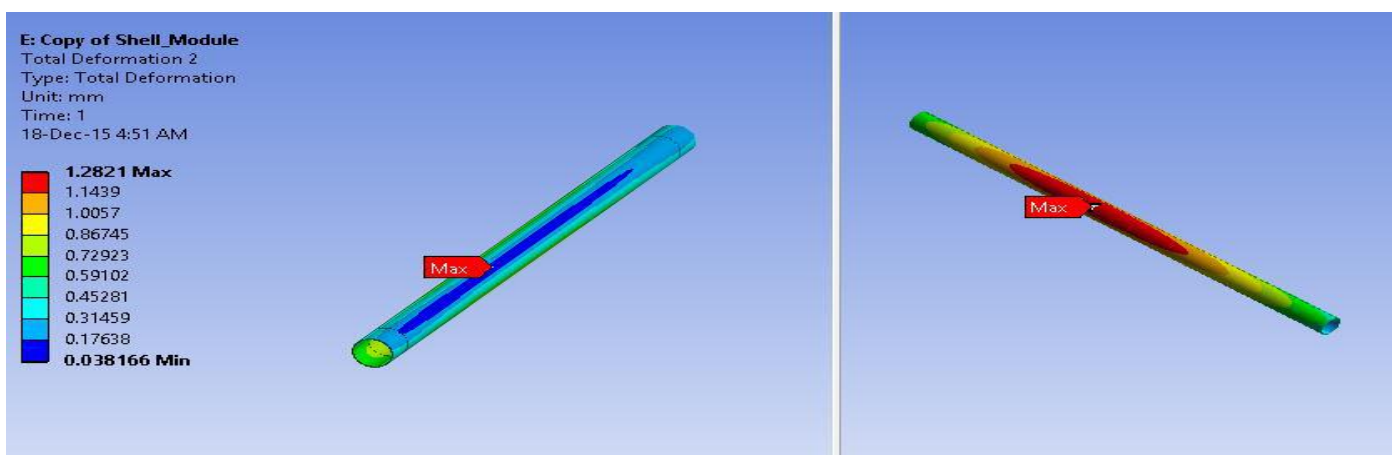

Fig. 4(a): Previous work model of Steel Propeller Shaft showing results for total deformation

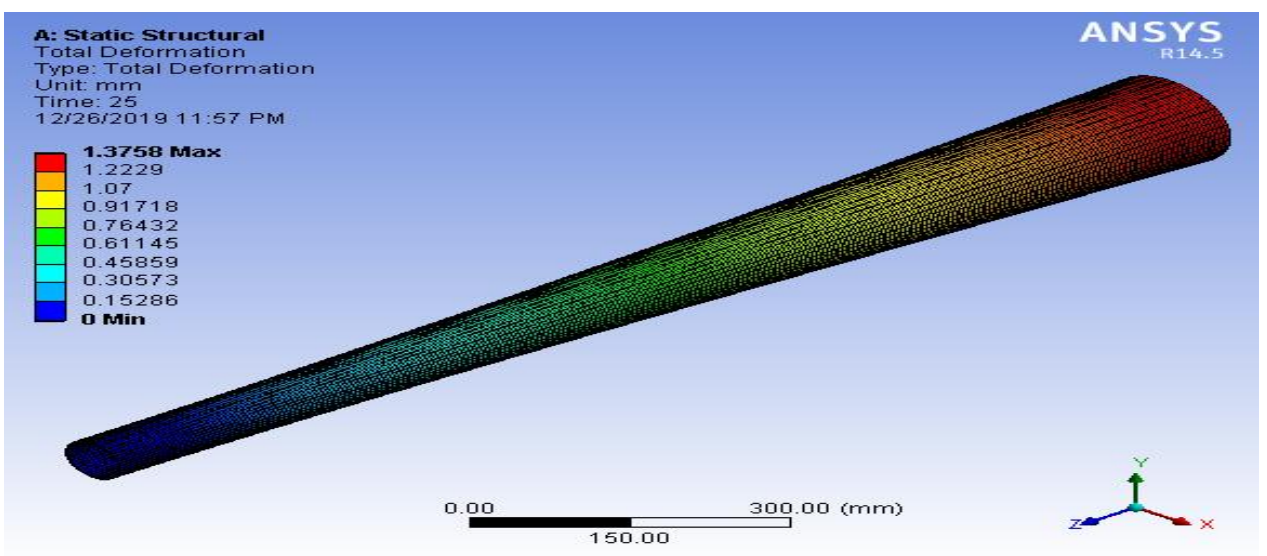

Fig. 4(b): Present work model of Steel Propeller Shaft showing results for total deformation

\begin{tabular}{|c|c|c|}
\hline Work Done & Maximum deformation in $\mathbf{m m}$ & Difference in values in \% \\
\hline Previous & 1.2821 & \multirow{2}{*}{$93.18 \%$ accuracy } \\
\hline Present & 1.3758 & \\
\hline
\end{tabular}

The present work values and boundary conditions are given same as that of previous work. Load of $2500 \mathrm{~N}-\mathrm{m}$ is applied and we have made 25 iterations for the present work to get higher accuracy. By comparing the results of previous and present work the maximum and minimum deformations are similar i.e. $93 \%$ accuracy. So we can go ahead with the further analysis.

\section{RESULTS AND DISCUSSIONS}

Here we have carried out two types of analysis i.e. linear buckling and torsional buckling analysis. In linear buckling one end, i.e., left end of the shaft is fixed and load of $1500 \mathrm{~N}, 2500 \mathrm{~N}$ and $3500 \mathrm{~N}$ are applied at the other end so that the shaft compresses from both the ends in order to resist the load applied. But, in case of torsional buckling, left end of the shaft is fixed and moment of $1500 \mathrm{~N}-\mathrm{m}, 2500 \mathrm{~N}-\mathrm{m}$ and $3500 \mathrm{~N}-\mathrm{m}$ is applied at the other end (moment load in clockwise direction is applied to the right side face), so that the shaft is completely twisted and hence loses its original shape by resisting the moment applied. 
International Advanced Research Journal in Science, Engineering and Technology

Vol. 8, Issue 12, December 2021

DOI: 10.17148/IARJSET.2021.81206

5.1 Tensile Linear Buckling Analysis for Steel and Hybrid Composite Propeller Shafts

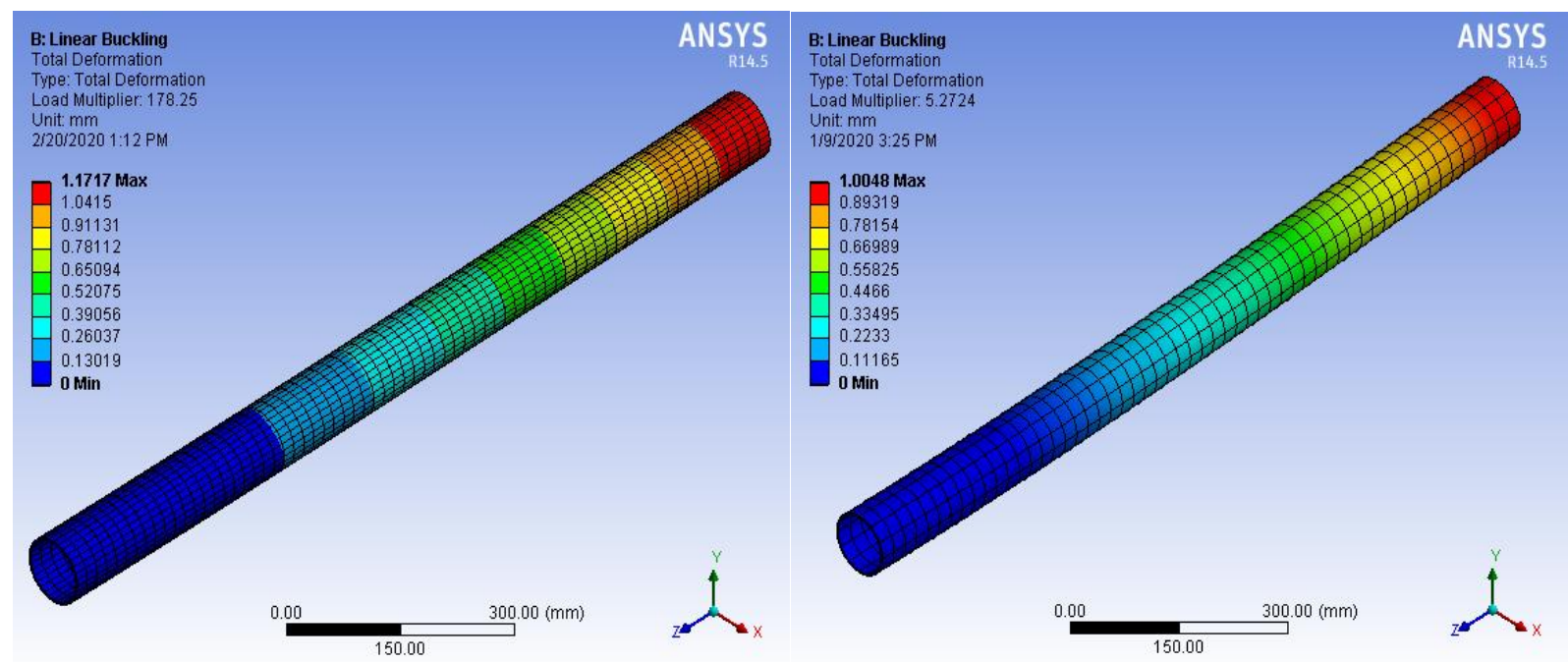

Fig. 5(a): Tensile Linear Buckling for Steel Shaft of load 1500N Fig. 5(b): Tensile Linear Buckling for Composite Shaft of load 1500N

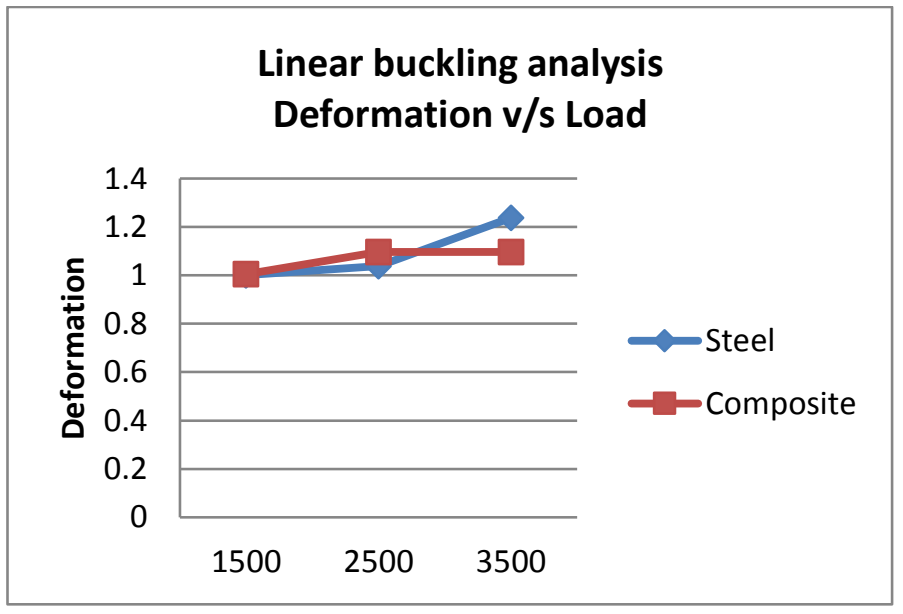

Graph 1: Tensile Linear buckling analysis for different load conditions

\begin{tabular}{|l|l|l|l|}
\hline \multicolumn{4}{|l|}{ Table3: Tensile Linear buckling analysis } \\
\hline $\begin{array}{l}\text { Deformation } \\
\text { (in mm)/ } \\
\text { Load }\end{array}$ & $\mathbf{1 5 0 0 N}$ & $\mathbf{2 5 0 0 N}$ & $\mathbf{3 5 0 0 N}$ \\
\hline Steel Shaft & 1.0010 & 1.0375 & 1.2375 \\
\hline $\begin{array}{l}\text { Composite } \\
\text { Shaft }\end{array}$ & 1.0048 & 1.0966 & 1.0966 \\
\hline
\end{tabular}

Figure 5 (a \& b), Graph1 and table 3 show the Tensile linear buckling analysis results of steel and composite propeller shaft. Here the load is applied in pull direction of the shaft and deformation for both steel and composite shafts evaluated and we can conclude that both steel and composite shaft show almost equal deformation. 
International Advanced Research Journal in Science, Engineering and Technology

Vol. 8, Issue 12, December 2021

DOI: 10.17148/IARJSET.2021.81206

5.2 Compressive Linear Buckling Analysis for Steel and Hybrid Composite Propeller Shafts

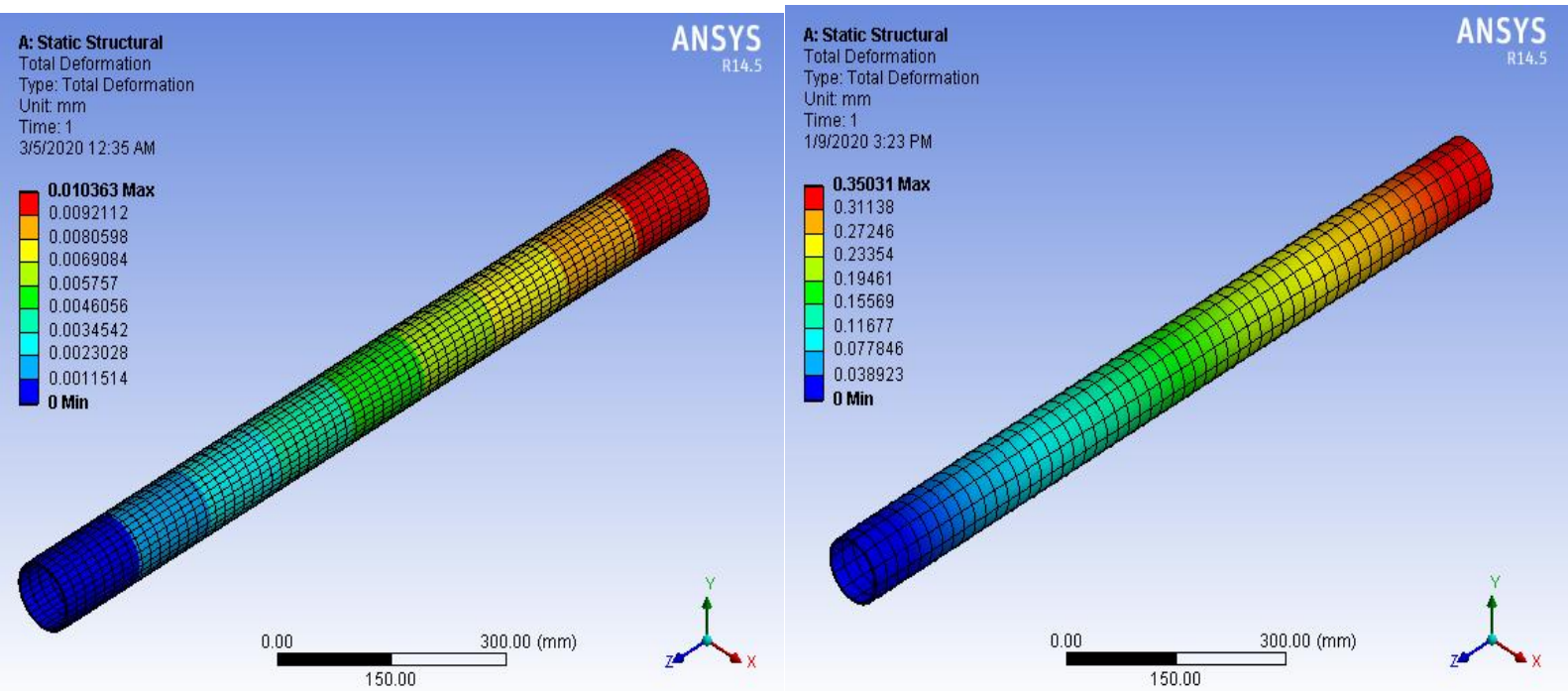

Fig. 6(a): Compressive Linear Buckling for Steel Shaft at load 1500N Fig. 6(b): Compressive Linear Buckling for Composite Shaft at load $1500 \mathrm{~N}$

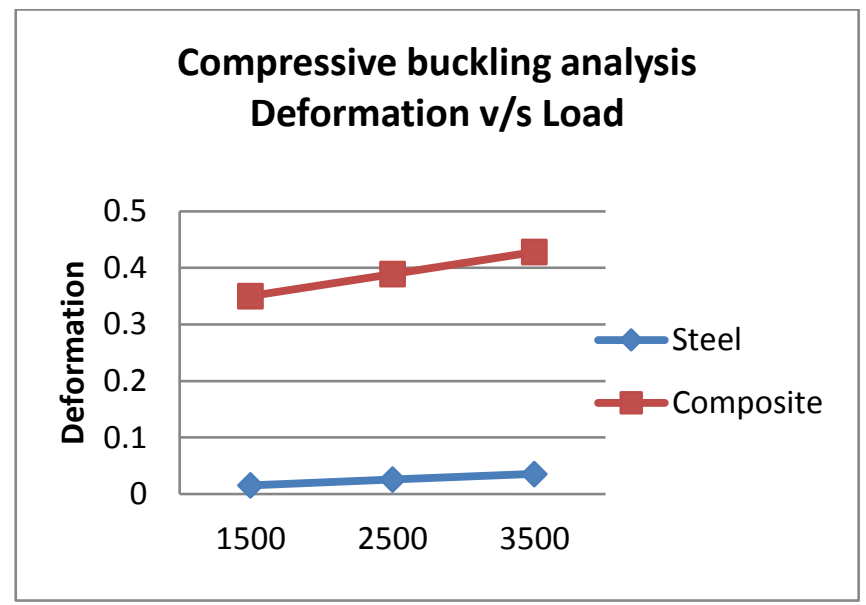

Graph 2: Compressive Linear buckling analysis for different load conditions

\begin{tabular}{|l|l|l|l|}
\hline \multicolumn{3}{|c|}{ Table 4: Compressive linear buckling analysis } \\
\hline $\begin{array}{l}\text { Deformation } \\
\text { (in mm)/ } \\
\text { Load }\end{array}$ & $\mathbf{1 5 0 0 N}$ & $\mathbf{2 5 0 0 N}$ & $\mathbf{3 5 0 0 N}$ \\
\hline Steel Shaft & 0.0153 & 0.0255 & 0.0357 \\
\hline $\begin{array}{l}\text { Composite } \\
\text { Shaft }\end{array}$ & 0.3503 & 0.3892 & 0.4282 \\
\hline
\end{tabular}

Figures 6(a \& b), Graph2 and table 4 show the Compressive linear buckling analysis results of steel and composite propeller shaft. Here the load is applied in push direction of the shaft and deformation for both steel and composite shafts evaluated. Comparative results show that the Steel shafts show the minimum deformation by which it can be concluded that steel shafts can withstand more loads than the composite shafts. 
Vol. 8, Issue 12, December 2021

DOI: 10.17148/IARJSET.2021.81206

\subsection{Torsional Buckling Analysis for Steel and Hybrid Composite Propeller Shafts}
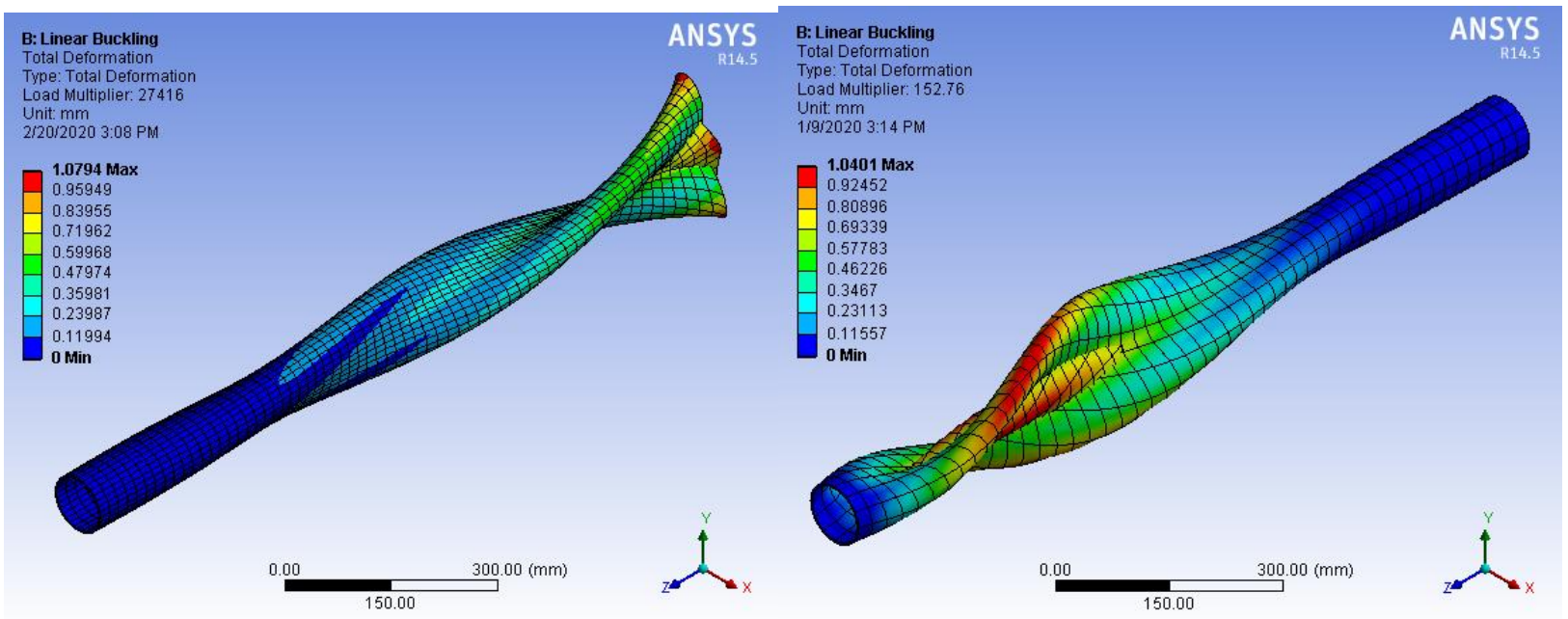

Fig. 7(a): Torsional Buckling for Steel Shaft of moment 1500N-m Shaft of moment $1500 \mathrm{~N}-\mathrm{m}$

Fig. 7(b): Torsional Buckling for Composite

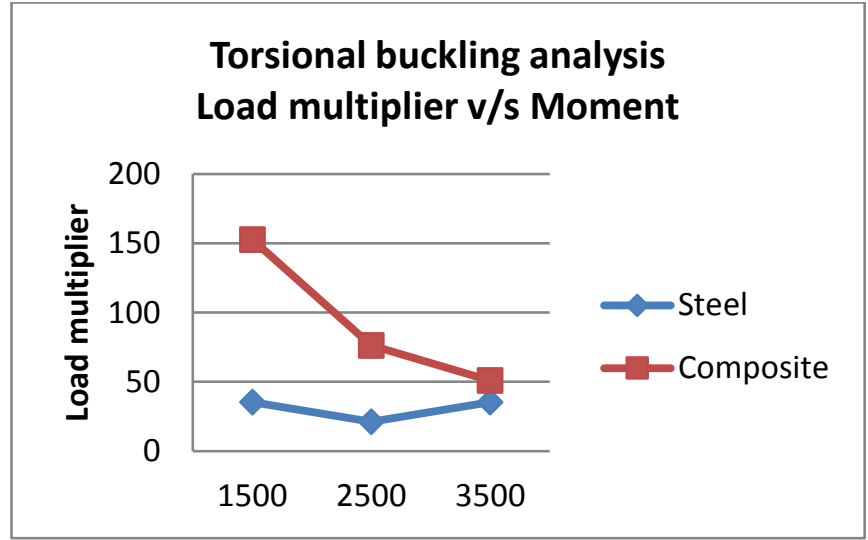

\section{Graph 3: Torsional buckling analysis for different Moment conditions}

\begin{tabular}{|l|l|l|l|}
\hline \multicolumn{4}{|l|}{ Table 5: Torsional buckling analysis } \\
\hline $\begin{array}{l}\text { Load multiplier } \\
\text { /Moment }\end{array}$ & $\mathbf{1 5 0 0 N}-\mathbf{m}$ & $\mathbf{2 5 0 0 N}-\mathbf{m}$ & $\mathbf{3 5 0 0 N}-\mathbf{m}$ \\
\hline Steel Shaft & 35.386 & 21.232 & 35.386 \\
\hline Composite Shaft & 152.76 & 76.381 & 50.921 \\
\hline
\end{tabular}

Figures 7(a \& b), Graph3 and table 5 show the torsional buckling analysis results of steel and composite propeller shaft. Here the load multiplier for both steel and composite shafts evaluated.

\section{CONCLUSION}

Linear buckling analysis results show that when the tensile loads are applied, the deformation for both steel and composite shafts show almost equal deformation which means that both steel and hybrid composite propeller shafts have equal capacity to withstand loads. But, when the compressive loads are applied, steel shafts show the smaller deformations compared to the hybrid composite propeller shafts which means that steel shaft can carry more loads. Further, from the torsional buckling analysis it is seen that the hybrid composite shafts got maximum load multiplier than the steel shafts.

Therefore from the results we can conclude that steel propeller shafts can be replaced by the Hybrid Composite Propeller shafts consisting of low carbon steel, epoxy, S- glass and T700 fibers which ultimately reduces the weight of the propeller shaft and hence increases the performance of the automobiles and air vehicles. 


\title{
International Advanced Research Journal in Science, Engineering and Technology
}

\author{
Vol. 8, Issue 12, December 2021
}

DOI: $10.17148 /$ IARJSET.2021.81206

\section{REFERENCES}

1. R. Harimaheswaran, N.Jeyakumar, R.Satheeshkumar, P.Viswabharathy. "Design Optimization and Analysis of Propeller Shaft" International Journal of Emerging Technologies in Engineering Research (IJETER) Volume 5, Issue 4, April (2017).

2. Shivanand\& Dr. Shravankumar B. Kerur, "Failure and Thermal Examination of hybrid materials for a propeller shaft in aerospace applications", 'International Journal of Recent Technology and Engineering (IJRTE)', 2019:8(2):6422-6428.

3. Kishor Ghatage, Narayanrao Hargude, "Static, Modal And Buckling Analysis Of Automotive Composite Drive Sahft”, ISSN: 2278-1684, PP: 3242

4. T.Ravi , P.Kanagaraj, "Numerical and Buckling Analysis of Composite Hybrid Propeller Shaft”, www.ijraset.com, Volume 3 Issue XI, November 2015

5. Mr. A.R. Nadaf, Dr.V.A.Raikar, "Design \& Analysis of Composite Shaft of Passenger Vehicle”, www.ijraset.com ,Volume: 04 Issue: 08 | Aug 2017

6. Amim Altaf Baig, Dr. A.M. Langde, "Design, Failure Analysis and Optimization of a Propeller shaft for HMV”, IJISET - International Journal of Innovative Science, Engineering \& Technology, Vol. 2 Issue 10, October 2015.

7. Dr.R.Ganapathi, Dr.B.Omprakash, J.Vinay Kumar, "Modeling and Analysis of Composite Propeller Shaft", International Journal of Latest Engineering Research and Applications, 2017: 02(11):24-28.

8. M. Pallavi1, T. Joel Swaroop Raj, A. Syam Prasad, M.Madhavi, "Experimental Investigations on Static and Dynamic Parameters of Steel and Composite Propeller Shafts for a Light Passenger Vehicle", IOSR Journal of Mechanical and Civil Engineering. 2015:12(4):01-07.

9. Atul Kumar Raikwar, Prof. Prabhash Jain \& Rajkumari Raikwar, Design and optimization of automobile propeller shaft with composite materials using FEM Analysis", 2016:4(4):39 - 48.

10. Miss Priya Dongare, Dr. Suhas Deshmukh, "Static and Modal Analysis of Composite Drive Shaft and Development Of Regression Equations", International Journal of Engineering Research \& Technology, 2012:1(10):1 -6

11. Shrikant Reddy "Evaluation on the failure of an automobile drive shaft" International journal on latest trends in engineering technology, 2017:8(3):59-67.

12. Sheik A. N. S "Design to replace steel drive shaft in an automobile with hybrid aluminum metal matrix composites" International journal and magazine of Engineering and technology, 2017:4(6):294-301.

13. G V Mahajan "Composite Material: A Review over Current Development and Automotive Application” IJOSR, 2012: 2(11):01 - 06.

14. V S Bhajantri "Design and analysis of composite drive shaft" IJRET, ISSN-2319-1163

15. Bhirud Pankaj Prakash "Analysis of drive shaft" international journal of mechanical and production engineering, 2013:2(2):1955- 1960.

16. S R Dharmadhikari "Design and analysis of composite drive shaft using ANSYS and GA" IJOR, 2013: 3(1):490-496.

17. Swapnil Shinde, "Design and Optimization of Propeller Shaft Made Up of Composite Material", International Engineering Research Journal Page No 1046-1053. 